\title{
Time-lapse technic used to uncover the naturel growth of osteochondromas of the wrist in patients with Hereditary Multiple Osteochondromas
}

\author{
Heleen M. Staal ${ }^{* 1}$, John Derwall ${ }^{2}$, Adhiambo M. Witlox ${ }^{1}$, Lodewijk W. van Rhijn ${ }^{1}$ \\ ${ }^{1}$ Department of Orthopaedic Surgery, Research school CAPHRI, Maastricht University Medical Centre (MUMC+), Maastricht, \\ The Netherlands \\ ${ }^{2}$ Medicorporate, Maastricht, The Netherlands
}

Received: February 27, 2017

Accepted: May 24, 2017

Online Published: June 8, 2017

DOI: $10.5430 /$ ijdi.v4n2p57

URL: https://doi.org/10.5430/ijdi.v4n2p57

\begin{abstract}
Background: In patients with Hereditary Multiple Osteochondromas (HMO) shortening and deformity of the long bones is a well-known sequel. Several theories could clarify the cause of shortening or deformity.

Methods: To reveal the development of the long bones and the influence of the osteochondromas on the growth we used time-lapse technique. Radiographic images, taken for clinical reasons, of $6 \mathrm{HMO}$ affected patients with known osteochondromas on the distal end of the lower arm were selected and adapted to make them suitable for use with a time-lapse technique. The images were placed in chronological order. The ulnar shortening, lunate position and radial inclination were registered, as were the clinical problems. The hypothesis being that slow occurring developmental deformities are easier comprehended and qualitatively studied when the changes are accelerated.

Results: None of the patients had radial head dislocation at the elbow. The majority of the wrists had decreased ulnar length and increased radial inclination. The clinical problems were limited. The osteochondromatic growth did not seem related to the wrist growth, but when the inclination of the radius was steep osteochondromas were present in the distal radius and the ulna was shortened. Some osteochondromas disappeared.

Conclusions: Time-lapse videos of wrists of patients with HMO showed no relation between growth of wrists and osteochondromas but it did show osteochondromas disappearing. A steep radial inclination seems related to ulnar shortening and might be due to proximity of radial osteochondromas. Patients had marked radiological changes, but relatively few clinical problems.
\end{abstract}

Key Words: Multiple Osteochondromas, Hereditary Multiple Osteochondromas, Time-lapse, Wrist

\section{INTRODUCTION}

Patients with Hereditary Multiple Osteochondromas (HMO) or Hereditary Multiple Exostosis suffer from an autosomal dominant inherited disease that causes osteochondroma formation. Osteochondromas are characterised by the outward growth of cartilage-capped bone tumors on the long bones; the bone marrow cavity is continuous with the normal bone cavity. ${ }^{[1,2]}$ They are most often found on the metaphysis. Osteochondromas develop in the first decade of life and cease to grow until the patient reaches skeletal maturity. Patients with HMO can suffer from pain and discomfort when osteochondromas put pressure on the overlying structures such as

\footnotetext{
*Correspondence: Heleen M. Staal; Email: h.staal@mumc.nl; Address: Department of Orthopaedic Surgery, Research school CAPHRI, Maastricht University Medical Centre (MUMC+), Maastricht, The Netherlands.
} 
tendons, nerves or even the spinal cord. ${ }^{[3]}$ Besides discomfort and pain in almost half the population, HMO leads to growth disturbances including Madelung-like deformity (40\%-60\%), unequal limb length (10\%-50\%), joint deformity (2\%-55\%) and a disproportionally short stature $(37 \%-45 \%) .{ }^{[4-7]}$ The deformities slowly develop over time during skeletal growth.

About half of the patients develop wrist deformities resembling Madelungs deformity. Madelungs deformity was first described by Otto W. Madelung in 1878 as an epiphyseal growth plate disturbance characterized by dorsal and radial bowing of the radius. ${ }^{[8]}$ In HMO patients a forearm pseudoMadelungs deformity is described with shortening of the ulna and secondary bowing of the radius. ${ }^{[9]}$ The deformity has cosmetic effects and decreases grip strength. Treatment remains controversial since the outcome is moderate. ${ }^{[10,11]}$

The aim of this study is to increase understanding of development of the wrist in HMO over time. To visualize the slow developing deformity the time-lapse technic is used. The hypothesis being that slow occurring developmental deformities are easier comprehended and qualitatively studied when the changes are viewed in accelerated sequence.

\section{Patients And method}

In general if growth is slow it is difficult to visualize. To facilitate the observer we can accelerate the growth of the viewed subject by taking images of the subject at regular times during growth and view them in an accelerate way just like we can, for example, observe a tree growing over 30 years time in a one minute timeframe. This technique is called time-lapse. Time-lapse is defined as "photographic technique of taking a sequence of frames at set intervals to record changes that take place slowly over time". This time-lapse technique was used on radiographs taken of 11 wrists of 6 patients diagnosed with HMO with at least one osteochondroma on the distal forearm. The anterior-posterior and lateral radiographs of the wrists were collected over a minimum of 5 years. The patients' ages varied between 7 and 15 .

All of the selected wrist images were identically scaled and then framed in a similar fashion. The grey scale was adjusted using adobe Photoshop. In the frames the anteriorposterior images were placed in a chronological order by using Keynote. To properly outline the images a fixed point was selected at the base of the osteochondroma nearest to the radial epiphysis. The view time per image was 3 seconds. In all images the ulnar shortening, lunate position and radial inclination were registered and shown in the last image (see Figure 1). The clinical problems of the wrist were registered from the patient charts.

\section{Ethical review committee statement}

The study involves human data, but our ethical board has granted a waiver or the study does not require approval in our country, therefore an ethical approvement is not necessary.

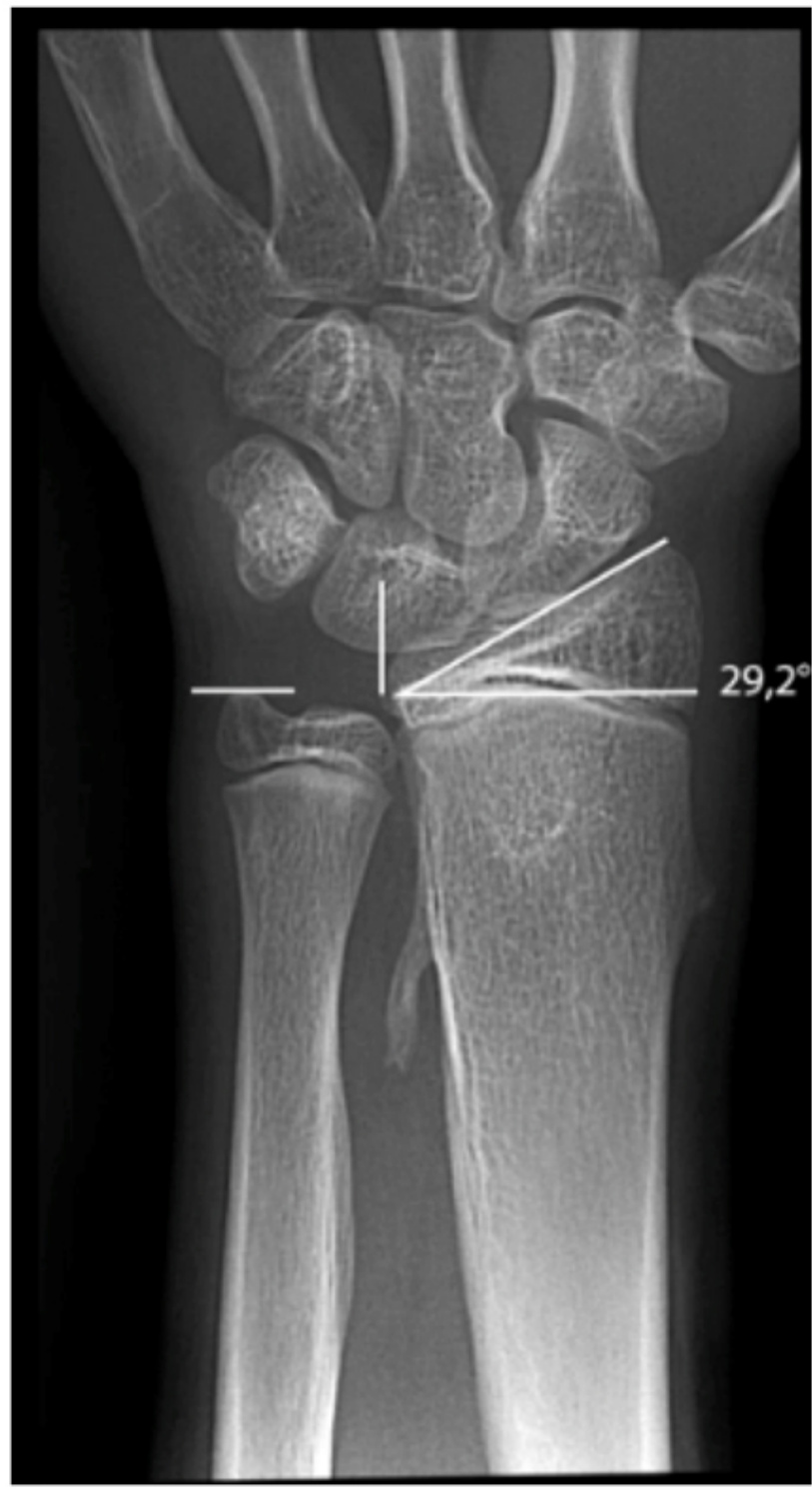

Figure 1. Still from video 10, last frame showing radial inclination of 29.2 degrees and a osteochondroma of the radius on the ulnair side

\section{Results}

Videos of the wrists can be viewed on webpage: https: //orthopedie.mumc.nl/hme-mo-videobeelden-van -de-ontwikkeling-van-exosten. All of the forearms had distal osteochondromas, 3 on the radius alone, 1 on the ulna alone and 7 on both ulna and radius. Patient nr 10 underwent a resection of a large osteochondroma. Of all 11 wrists, 9 had a shortening of the ulna. The inclination of the 
radius was increased in all patients (above 25 degrees) and over 30 degrees in 6 of the 11 wrists. The lunate was slipped over $50 \%$ in 3 of the 11 cases and between $25 \%-50 \%$ in the remaining 8 .

\section{Clinical problems}

None of the patients had a radial head dislocation at the elbow. Two patients had a marked ulnar drift and a decreased radial movement from 10 degrees. In one of these two patients the volar flexion was limited to 50 degrees. One patient had a limited supination of 70 degrees. One patient used a wrist brace for pain relief during repetitive activities.

Adapting the radiographs in this manner showed the growth of osteochondromas in relation to the growth of the wrists. In the ulnar length no clear relation could be found with the proximity of osteochondromas on the distal ulna. The radial deformity seemed more sever when osteochondromas were present in its proximity (5 out of 6 ) of the distal radius. It also seemed related to the shortening of the ulna (6 out of 6).

Remarkably in the videos of patient $\mathrm{nr} 2$ and patient $\mathrm{nr} 9$, the osteochondromas on the ulnar side of the radius disappear, without surgical intervention.

\section{Discussion}

In the selected wrists the majority had shortening of the ulna and increased radial inclination. Only 3 out of the 11 wrists showed a carpal slip over $50 \%$. The deformity of the wrists in HMO develops slowly over time and can be visualized using the time-lapse technic. The study shows that some patients had a gradually shorting of the ulna, which was not directly depending on the growth of osteochondromas. The radial deformity seems more depended on the proximity of radial osteochondromas.

The described development of a Madelung-like deformity at the wrists of about half of the HMO affected patients could not completely be seen in the patients from this study. ${ }^{[12-14]}$ The described shortening of the ulna however was clearly visible in the majority of the patients. In our patient group only one patient suffered from wrist pain and three patients had decreased wrist function. One patient was operated upon to resect a large radial osteochondroma oppressing the ulna. Even after resection this patient had a decreased volar flexion. The involvement of the upper-limb bones by HMO should be associated with greater loss of function because of the paired bones as described by Abe et al., ${ }^{[15]}$ but many authors underline that deformities of the upper extremity in patients who have HMO are well tolerated and lead to little loss of function as seen in our study. ${ }^{[16-19]}$

The relationship between the ulnar length and the sliding of

Published by Sciedu Press the lunate could not be found. However there seemed to be a relationship between the radial inclination and the ulnar shortening.

A study by Burgess et al. described no correlation between the radial articular angle and the ulnar position. ${ }^{[13]}$ However, the study by Gottschalk et al. - who separated the different types of forearm deformity - found a correlation between the growth arrests in the ulna, caused by osteochondromas, that preceded the deformity seen in the distal radius in one subgroup. ${ }^{[12]}$ Possibly in some types of growth disturbance the ulnar growth can influence the radial development or vice versa.

The most obvious deformity in the HMO wrists is the ulnar shortening. This automatically leads to a disruption of the distal radio-ulnar joint (DRUJ). Many others have described this problem. ${ }^{[14,20-22]}$ Notwithstanding the joint deformity, the function of the DRUJ stays intact. However, the marked shortening is considered important in the planning of treatment for forearm deformities. ${ }^{[12-15,22-26]}$ Some advocate early aggressive management to prevent deformity and disability ${ }^{[14,17,21-23,26-31]}$ and others are more conservative and have reported satisfactory function in skeletal mature patients without surgical intervention. ${ }^{[4,16]}$ The natural history of wrist deformity in HMO remains unknown and the role and timing of surgical treatment therefore controversial. Perhaps monitoring the changes over time can help unraveling the natural history. Time-lapse technic itself is very suited for monitoring changes in time. However, the presented study has limitations and disadvantages. The first limitation is the difference in projection of the wrists. Not all of the radiographs are taken in the exact same position. The position of the wrist and hand vary in several images making it more difficult to compare the successive images. The second limitation is the difference in time in-between the radiographs. Not all intermediate times were similar making the interpretation of the changes difficult.

A clearly disappearing osteochondroma was found in two patients. Yanagawa et al. described the disappearing of osteochondromas in 2001. ${ }^{[32]}$ They considered recovery of normal skeletal growth control as most likely mechanism. They further stated that in osteochondromas with fracture an alteration of vascular supply might contribute to growth arrest. In the two patients in this study no fracture of the osteochondromas was seen.

A disadvantage of taking multiple radiographs is exposing children to ionizing radiation. Besides the exposure to radiation the radiographs only show a two-dimensional image. In future studies the use of standardized MR images of the wrist used in a time-lapse manner could counter these disad- 
vantages. These images could show the epiphyseal cartilage and the deformity of the joints more clearly, making a threedimensional time-lapse possible. Hopefully this will lead to a better understanding of the developmental deformities in the wrists of HMO patients.

\section{Conclusion}

Time-lapse technique is suitable to monitor growth of wrists in HMO patients. It showed no direct relationship between growth of wrists and osteochondromas but it did show osteochondromas disappearing. A steep radial inclination seems related to ulnar shortening and might be due to proximity of radial osteochondromas. Patients had marked radiological changes, but relatively few clinical problems.

\section{Conflicts OF InTEREST Disclosure}

The authors have no conflict of interest related to this publication.

\section{REFERENCES}

[1] Khurana JA. World Health Organization Classification of Tumours Pathology and Genetics of Tumours of Soft Tissue and Bone. 2002. 234-36 p

[2] Bovee JV. World Health Organization Classification of Tumours. Pathology and Genetics of Tumours of Soft Tissue and Bone. 2002. 360-362 p.

[3] D'Ambrosi R, Ragone V, Caldarini C, et al. The impact of hereditary multiple exostoses on quality of life, satisfaction, global health status, and pain. Arch Orthop Trauma Surg. 2017 Feb; 137(2): 209-215. PMid:27933382 https://doi.org/10.1007/s00402-016-260 8-4

[4] Schmale GA, Conrad EU, Raskind WH. The natural history of hereditary multiple exostoses. J Bone Joint Surg Am. 1994; 76(7): 98692. PMid:8027127 https ://doi.org/10.2106/00004623-199 407000-00005

[5] Legeai-Mallet L, Munnich A, Maroteaux P, et al. Incomplete penetrance and expressivity skewing in hereditary multiple exostoses. Clin Genet. 1997; 52(1): 12-6. PMid:9272707 https ://doi .org/ 10.1111/j.1399-0004.1997.tb02508.x

[6] Bovee JV. Multiple osteochondromas. Orphanet J Rare Dis. 2008; 3 : 3. PMid:18271966 https://doi.org/10.1186/1750-1172-3 $-3$

[7] Goud AL, de Lange J, Scholtes VA, et al. Pain, physical and social functioning, and quality of life in individuals with multiple hereditary exostoses in The Netherlands: a national cohort study. J Bone Joint Surg Am. 2012 Jun 6; 94(11): 1013-20. PMid:22637207 https://doi.org/10.2106/JBJS.K.00406

[8] Madelung O. Die spontane subluxation de hand nach vorne. Verhandlungen der deutschen Gesellschaft fur Chirurgie. 1878; 7: 259-276.

[9] Vanhoenacker FM, Van Hul W, Wuyts W, et al. Hereditary multiple exostoses: from genetics to clinical syndrome and complications. Eur J Radiol. 2001 Dec; 40(3): 208-17. https : //doi.org/10.1016/ S0720-048X (01) 00401-6

[10] Akita S, Murase T, Yonenobu K, et al. Long-term results of surgery for forearm deformities in patients with multiple cartilaginous exostoses. Bone Joint Surg Am. 2007 Sep; 89(9): 1993-9. https: //doi.org/10.2106/00004623-200709000-00015

[11] D'Ambrosi R, Barbato A, Caldarini C, et al. Gradual ulnar lengthening in children with multiple exostoses and radial head dislocation: results at skeletal maturity. J Child Orthop. 2016 Apr; 10(2): 127-33. PMid:26910403 https://doi.org/10.1007/s11832-016-071 8-8

[12] Gottschalk HP, Kanauchi Y, Bednar MS, et al. Effect of osteochondroma location on forearm deformity in patients with multiple hereditary osteochondromatosis. The Journal of Hand Surgery. 2012.
[13] Burgess RC, Cates H. Deformities of the forearm in patients who have multiple cartilagenous exostosis. J Bone Joint Surg. 1993. 13-18 p. https://doi.org/10.2106/00004623-199301000-00003

[14] Peterson HA. Deformities and problems of the forearm in children with multiple hereditary osteochondromata. J Pediatr Orthop. 1994; 14: 92-100. PMid:8113381 https://doi.org/10.1097/012413 98-199401000-00019

[15] Abe M, Shirai H, Okamoto M, et al. Lengthening of the forearm by callus distraction. J Hand Surg. 1996. 151-163 p. https : //doi .org/10.1016/S0266-7681 (96)80090-8

[16] Stanton PR, Hansen MO. Function of the upper extremities in hereditary multiple exostoses. J Bone Joint Surg. 1996. 568-573 p. https ://doi.org/10.2106/00004623-199604000-00010

[17] Arms DM, Strecker WB, Manske PR, et al. Management of forearm deformity in multiple hereditary osteochondromatosis J Pediatr Orthop. 1997 Jul-Aug; 17(4): 450-4. PMid:9364381 https : //doi.org/10.1097/01241398-199707000-00007

[18] Watts AC, Ballantyne AJ, Fraser M, et al. The Association Between Ulnar Length and Forearm Movement in Patients With Multiple Osteochondromas. The Journal of Hand Surgery. 2007; 32(5): 667-673. PMid: 17482006

[19] Clement ND, Porter DE. Forearm deformity in patients with hereditary multiple exostoses: factors associated with range of motion and radial head dislocation. J Bone Joint Surg Am. 2013 Sep 4; 95(17): 1586-92. PMid:24005199 https://doi.org/10.2106/ JBJS.L. 00736

[20] Solomon L. Bone growth in diaphyseal aclasis. J Bone Joint Surg. 1961. 700-716 p.

[21] Fairbank HAT. Diaphyseal aclasis. J Bone Joint Surg. 1949. 105-113 p.

[22] Fogel GR, McElfresh EC, Peterson HA, et al. Management of deformities of the forearm in multiple hereditary osteochondromas. $\mathbf{J}$ Bone Joint Surg. 1984. 670-680 p. https://doi.org/10.2106/ 00004623-198466050-00004

[23] Bader B, Grill F. Ulnar lengthening in osteochondroma of the forearm. Handchir Mikrochir Plast Chir. 2000. 321-327 p. PMid:11103689 https://doi.org/10.1055/s-2000-10943-1

[24] Cheng JC. Distraction lengthening of the forearm. J Hand Surg. 1991. 441-445 p. https ://doi.org/10.1016/0266-7681(91) 90023 $-\mathrm{H}$

[25] Dahl MT. The gradual correction of forearm deformities in multiple hereditary exostoses. Hand Clin. 1993. 707-718 p. PMid:8300740 https ://doi .org/10.1016/S0363-5023(85)80074-5

[26] Masada K, Tsuyuguchi Y, Kawai H, et al. Operation for forearm deformity caused by multiple osteochondromas. J Bone Joint Surg. 1989. 24-29 p. 
[27] Wood VE, Sauser D, Mudge D. The treatment of hereditary multiple exostosis of the upper extremity. J Hand Surg. 1985. 505-513 p.

[28] Peterson HA. Multiple hereditary osteochondromata. Clin Orthop. 1989. 222-230 p. https : //doi .org/10.1097/00003086-19890 2000-00026

[29] Pritchett JW. Lengthening the ulna in patients with hereditary multiple exostoses. J Bone Joint Surg. 1986. 561-565 p.

[30] Raimondo RA, Skaggs DL, Rosenwasser MP, et al. Lengthening of pediatric forearm deformities using the Ilizarov technique: functional and cosmetic results. J Hand Surg. 1999. 331-338 p. https://doi.org/10.1053/jhsu.1999.0316

[31] Rodgers WB, Hall JE. One-bone forearm as a salvage procedure for recalcitrant forearm deformity in hereditary multiple exostoses. $\mathrm{J}$ Pediatr Orthop. 1993; 13: 587-591. PMid:8376557 https://doi. org/10.1097/01241398-199309000-00006

[32] Yanagawa T, Watanabe H, Shinozaki T, et al. The natural history of disappearing bone tumours and tumour- like conditions. Clin Radiol. 2001; 56: 877-886. PMid:11603890 https://doi.org/10.1053/ crad.2001.0795 